ISSN: 1641-4713; e-ISSN: 2081-1160

DOI: https://doi.org/10.36551/2081-1160.2020.26.265-290

\title{
Imaginación cosmológica, espiritualidad católica y sensibilidad contemplativa: la meditación cristiana en Argentina
}

\author{
Cosmologic imagination, Catholic spirituality and contemplative \\ sensibility: Christian meditation in Argentina
}

Gustavo A. Ludueña

CONICET - Escuela IDAES

Universidad Nacional de San Martín, Argentina

ORCID iD: https://orcid.org/0000-0002-5163-9352

E-mail: galuduena@hotmail.com

Recepción: 30.04 .2020

Aprobación: 26.11.2020

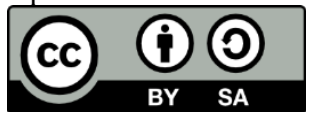

Resumen: Este artículo analiza la dimensión cosmológica de la práctica de la "meditación cristiana" en Argentina, la cual es definida como una manifestación laical posconciliar inspirada en una sensibilidad contemplativa. En el estudio se identifican dos ejes que estructuran la cosmología de esta forma de meditación. A saber, la perspectiva ecuménica centrada en una narrativa sobre Oriente y la patrística; $y$, en segundo lugar, una noción de persona orientada hacia la interioridad, la intimidad divina y el bienestar. La investigación concluye que esta cosmología da lugar a una espiritualidad católica alternativa a partir de un desplazamiento ontológico respecto de valores religiosos de la iglesia. En este sentido, la secularización de la meditación disuelve la tensión entre religión y espiritualidad, y desarrolla una autonomía personal no individualista en los meditadores.

Palabras clave: espiritualidad, meditación, secularización, Oriente, ritual.

Abstract: This article analyses the cosmological dimension of the practice of "Christian Medita-
tion" in Argentina, which is envisioned as a post-Vatican II laity movement inspired by a contem-
plative sensitivity. The study identifies two axes that structure this form of meditation. Firstly, there
is an ecumenical perspective centered around a mythical narrative about the East and the patristics;
and, on the other hand, a notion of person oriented toward interiority, intimacy with divinity and 
wellbeing. The research states that this cosmology makes room for an alternative Catholic spirituality because of an ontological displacement from religious values of the church. In this sense, the secularization of meditation erases the distinction between religion and spirituality and develops a personal non-individualistic autonomy among meditators.

Keywords: spirituality, meditation, secularization, East, ritual.

\section{INTRODUCCIÓN}

Las miradas sobre la espiritualidad suelen concebirla como algo opuesto -y aun como reacción- a la religión. Bajo esta óptica, ambas categorías operan como taxonomías analíticas autoexcluyentes para caracterizar universos de experiencia en apariencia divisibles. Al mismo tiempo, cualquiera que sea la relación que entablen con lo numinoso (Otto, 1980), sea adscripta a una teología trascendente o inmanente, se las sitúa en las antípodas de lo secular (van der Veer, 2014). En el catolicismo, por ejemplo, la historia muestra la formación de numerosas formas de espiritualidad que convivieron en marcos institucionales con grados diversos de tensión, tal como sucedió con la aparición de congregaciones y órdenes religiosas identificadas luego con un determinado "carisma". Haciendo foco en la cosmología, este artículo analiza la acogida de la "meditación cristiana" en el catolicismo argentino, mostrando su matriz anfibia entre espiritualidad y religión.

Para este estudio, utilizo material empírico reunido en el movimiento de Meditación Cristiana de Argentina, el cual pertenece a The World Community for Christian Meditation y postula una espiritualidad que gira en torno a la práctica de la meditación. Esta última está inspirada en experiencias previas del cristianismo y en el diálogo con modos orientales de meditar (Freeman, 2009; Main, 2006, 2014). En este espacio de meditación, revisé y analicé varias de sus publicaciones, hice entrevistas a sus miembros y realicé observación participante en reuniones semanales de grupos de meditadores. Asimismo, en el curso del trabajo de campo -que tuvo lugar con intermitencia entre 2011 y 2016- tomé contacto con el movimiento Oración Centrante ${ }^{1}$ y con la organización Vivir Agra-

\footnotetext{
${ }^{1}$ Contemplative Outreach fue formalmente creada en 1984 en Estados Unidos, siendo conocida en América Latina como Extensión Contemplativa Internacional. En respuesta al llamado del papa Pablo VI de principios de la década de 1970 sobre impulsar la vida contemplativa en el laicado, tres monjes cistercienses -William Menninger, Basil Pennington y Thomas Keating- desarrollaron un método de meditación a partir de la lectura del texto místico anónimo del siglo XIV La Nube del No Saber que derivó luego en lo que se llamó "oración centrante" (Keating, 1986).
} 
decidos ${ }^{2}$, en la cual concurrí a conferencias y presentaciones de libros sobre espiritualidad cristiana.

Divulgada en Argentina en los años que rodearon al cambio de siglo, la meditación cristiana consiguió instalarse con cierto éxito en espacios católicos. Este acomodamiento no fue lineal ni estuvo exento de tensiones con aquello que la Iglesia sostiene como dogmas, doctrinas y liturgias. Dicho aspecto evidencia las singularidades locales en comparación a su establecimiento en otras naciones con paisajes religiosos diferentes (Duerr, 2004; Mermis-Cava, 2009; Šķupele, 2015). Veremos que la meditación cristiana es un caso liminal cuya especificidad se da tanto por el ejercicio de una tecnología de cuidado de $\mathrm{si}^{3}$, como por la cosmología que le dio origen. Se sustenta en buena medida de la experiencia espiritual que propone, construida en parte de experiencias en Oriente y de la recuperación de prácticas remotas ancladas en el período patrístico y en el misticismo católico medieval y moderno (Ruffing, 2000). Todo esto se expresa en una novedosa forma de habitar el mundo para quienes suscriben a ella. En adición, la meditación deviene en una arena de disputa entre espiritualidad y religión, donde múltiples lecturas y apropiaciones reflejan las rivalidades existentes entre una y otra.

La meditación cristiana constituye una nueva espiritualidad en el catolicismo que se funda, según los relatos nativos, en una técnica arcana de oración de los primeros tiempos cristianos (Bourgeault, 2009; Keating, 1986, 1998b; Main, 2006, 2014) ${ }^{4}$. Además, registra vínculos con espiritualidades no cristianas a partir de representaciones generadas en torno a la meditación. En suma, me

\footnotetext{
${ }^{2}$ Vivir Agradecidos es la versión en habla hispana de Grateful Living, un organismo cofundado por el monje benedictino de origen austríaco David Steindl-Rast -conocido simplemente como "hermano David"- para divulgar la práctica cotidiana de "la gratitud". Esta última es definida como una actitud de agradecimiento personal, constante y proactiva de la cual se afirma que tiende a mejorar la calidad de vida de las personas y su lugar en el mundo; en especial, mediante un cambio profundo en las relaciones con el prójimo, con uno mismo y con el entorno.

${ }^{3}$ Para la noción de tecnología sigo a Foucault $(1991,2001)$. Sin embargo, para su aplicación a la meditación no utilizo el concepto solo como un instrumento para el cuidado y transformación de sí sino, más próximo a como la suelen entender las personas, como una acción del ser articuladora de una forma de vida y una particular disposición hacia el mundo. Veremos más adelante que, en este sentido, la meditación es tanto una tecnología como una cosmología y ontología.

${ }^{4} \mathrm{Si}$ bien refiero a "meditación cristiana", en términos generales la entiendo como parte de un segmento mayor que integra un giro laical global hacia la oración contemplativa -inspirado en los cambios conciliares, pero también en los contactos con Oriente y en su presencia creciente en el mundo occidental-. Dicho de otro modo, movimientos y expresiones que no necesariamente apelan a la práctica de la meditación como parte de su agenda ritual pero sí al silencio o la contemplación, estarían asociados a este movimiento más amplio del catolicismo. Siguiendo este criterio, en Argentina podrían incluirse expresiones como Soledad Mariana o el Centro de Espiritualidad Santa María, entre otras.
} 
detendré en el análisis de una espiritualidad basada en la práctica de la meditación que emana de un proceso de imaginación cosmológica en el que concurren elementos procedentes de distintos linajes religiosos. Sostendré que esta forma de meditación cristiana formula un corrimiento semántico y ontológico de la religión a una forma de espiritualidad cristianizada. Esta se caracteriza por un reencantamiento del mundo, el cual se observa y experimenta bajo la óptica de un horizonte hermenéutico remozado; es decir, de una cosmología que deja a la persona percibir, sentir y actuar en el mundo de forma novedosa, recomponiendo las relaciones con uno mismo, con los otros y con dios. Por dicha razón, se refuerza lo intersubjetivo más que lo individual. Así, pues, afirmaré que existe una continuidad entre religión -católica- y espiritualidad (Woodhead, 2011), consumada por mediaciones cosmológicas que estructuran esa relación. La persona conecta campos de experiencia y conocimiento diversos que le allanan el paso para explorar, testear y elaborar constelaciones alternativas de sentido.

Para desarrollar este argumento expondré primero las variaciones de la meditación, tal como se manifiestan en movimientos religiosos locales, estableciendo el lugar que ocupa la meditación cristiana en este paisaje social a partir de sus usos y sentidos. En segundo lugar, la analizaré como un significante que dialoga con órdenes cosmológicos disímiles, centrándome en el horizonte orientalista de su origen que sigue presente en las narrativas de sus adherentes. En este punto, la idea es mostrar la solidaridad semiótica que ellos encuentran entre elementos de una cosmología que, impugnable para ciertas miradas ortodoxas, son consistentes con redefiniciones en el imaginario de la meditación cristiana a través de analogías que hacen posible alcanzar nuevas síntesis. Por último, se verá de qué manera esta síntesis es solidaria con un reordenamiento cosmológico de la meditación y de la persona en relación con ella. Este aspecto se plantea como un retorno al sujeto, el cual se caracteriza por acentuar la vitalidad mística del espacio interior, el encuentro teísta íntimo a través del ritual y una condición existencial que reorienta el estar en el mundo bajo una performance que no se olvida de dios.

\section{SENTIDOS Y USOS DE LA MEDITACIÓN}

Distintos estudios sobre la meditación dan cuenta de su intervención en áreas como la educación, la salud, la política y el trabajo, consolidándose como una tecnología espiritual que posibilitaría obtener fines tan variados como asegurar el bienestar personal, mejorar la producción laboral, reducir el estrés, etc. (cf., Moraes 2014; Schmidt-Wilk et. ál., 1996; Thomas \& Cohen, 2014; Wach- 
holtz \& Pargament, 2005). En el marco más extenso de otras técnicas que compiten con ella en la esfera pública -como el reiki, acupuntura, biodecodificación, reflexología, etc.-, el desembarco del yoga y la meditación en el campo de la sanidad a partir de talleres de terapias complementarias fue investigado para establecer las apropiaciones en ámbitos seculares (Saizar, 2009; Saizar et ál., 2013), lo cual deja conocer cómo la meditación muda en eso que Moraes (2019) llama el "ejercicio desencantado de la salud".

En suma, estos trabajos abordan algunas de las múltiples formas de adopción de la meditación. A ellas se suman otras tantas como la meditación trascendental, meditación con mandalas, meditación vipassana, meditación guiada, meditación con cuencos tibetanos, la danza del vajra como "meditación en movimiento" en el budismo tibetano (Carini, 2016), etc. Entre los modos de meditación, puede decirse que fue el mindfulness el que ha despertado el mayor interés, quizás por su alta difusión tanto como por tratarse de una práctica meditativa secularizada. Al decir de Moraes (2019, p. 229), “[o]s termos atenção plena e mindfulness vem sendo mais difundidos para evitar a associação religiosa ou mágica que a palavra meditação denota"'. Precisamente, en este punto de tensión entre espiritualidad y religión, veremos que en la meditación cristiana se expresa en el terreno de lo cosmológico.

En esta dirección, hay investigaciones locales que analizan el rol simbólico de la meditación en entornos religiosos, como sucede con el movimiento de Sai Baba y los practicantes del budismo zen. En estos casos se exploran los nexos de la meditación con universos cosmológicos más amplios en los que representa uno de los caminos de relación con lo numinoso para lograr ciertos estados o experiencias como la iluminación o unión mística con dios (Puglisi, 2009). Así, la práctica del zazen en el budismo zen exhibe la forma en la que esta meditación resulta de interés a personas que atraviesan situaciones de alguna forma de dolor o sufrimiento (Carini, 2009). Asimismo, ilustra la manera en que los dolores intrínsecos a la postura corporal se anexan a esta acción ritual como el recordatorio constante del sufrimiento de la condición humana (Alves, 2004; D'Angelo, 2018). Las modalidades de meditación promovidas por las tradiciones soto y rinzai revelan igualmente la riqueza latente en la producción de la experiencia religiosa (Puglisi \& Carini, 2017). En este campo, el análisis sobre el zazen en Zendo

\footnotetext{
${ }^{5}$ Este mismo distanciamiento de lo religioso fue suficientemente tratado a partir de la antítesis expuesta en la fórmula spiritual but not religious que, principalmente en el mundo sajón, permitió dar cuenta de los dilemas identitarios en otros contextos socio-religiosos (véase, por ejemplo, Ammerman, 2014; Partridge, 2004; Wuthnow, 1993).
} 
Betania, una institución creada para la práctica del zen e integrada por personas con lazos católicos -sea en calidad de laicas o consagradas-, evidencian el valor que adjudican los asistentes a los aspectos rituales y a su potencial cosmológico para favorecer la relación con dios (Carini, 2012; Puglisi, 2018).

Otras investigaciones recientes dan cuenta de cruces simbólicos notables entre simbolismos y ontologías orientales y católicas. Estas apuntan a la sanación psicofísica y espiritual o, incluso, a la curación de enfermedades graves por medio de la oración (Olmos Álvarez, 2015) o a la meditación basada en la canalización de energías (Gracia, 2018; Monteros Gutiérrez, 2018). En este último caso, la acción terapéutica en la llamada "meditación de la Llave Mariana" -originada alrededor de un grupo de reikistas - se concreta a través de técnicas de visualización de contenidos que trazan sincretismos cosmológicos nutridos de imágenes del Sagrado Corazón de Jesús o del Arcángel Gabriel, junto con la recitación mántrica de rosarios para el desbloqueo de los chacras (Gracia, 2018). En otro caso de concurrencia de catolicismo y Nueva Era, más cerca de lo que Kemp (2004) bautizó como "cristianos de Acuario"-Christaquarians-, invoca una forma de "meditación guiada" y "angelical" que coexiste con rezos y apela a mantras, a Cristo, al tai chi y a los ángeles (Monteros Gutiérrez, 2018).

En el catolicismo también hubo lugar para la invención de tecnologías meditativas; ya fuera mediante la revisión de modalidades surgidas del misticismo cristiano o de la mirada a otras espiritualidades -en especial, orientales-, aparecieron formas innovadoras de meditar. Algunos ejemplos son la oración centrante (centering prayer) (Keating, 1986), la meditación cristiana (Freeman, 2009; Main, 2006, 2014) y la meditación interior cristiana (Christian insight meditation) (Cullingan et ál., 1994), la cual combina la espiritualidad carmelitana de San Juan de la Cruz con el budismo vipassana (Steele, 2000). Adicionalmente, de forma análoga a lo que sucede con el mindfulness, existen aplicaciones "secularizadas" de tecnologías cristianas de meditación para la salud; y así lo notaron Frederick y White (2015) para la práctica de la meditación centrante, meditación devocional cristiana y oración contemplativa. En idéntica línea, Hwang (2018) exhibe otro uso sanitario en el protestantismo a través de la "meditación escritural cristiana" (Christian Scripture meditation). Por su parte, la versión de la meditación cristiana, tal como se explora en este artículo, consiguió una penetración capilar en la vida cotidiana de católicos que la incorporaron como complementación o aun sustitución ritual a la oración convencional (Ludueña, 2018). En una visión sociohistórica mayor, este movimiento de incorporación de la meditación en espacios laicales de América Latina fue caracterizado como un nuevo ascetis- 
mo extramundano y aun como una forma sui generis de monaquismo secular (Ludueña, 2017). Precisamente, su circulación como conjunto heteróclito de saberes y prácticas de naturaleza contemplativa fue analizado en clave de la tensión existente con estructuraciones institucionales que acreditan su lugar periférico y liminar en el catolicismo (Ludueña, 2014). Debe notarse que, en estos casos, estas prácticas son encaradas por personas que permanecen en el horizonte cosmológico de la religión, lo cual presenta un contraste significativo con el empleo desencantado de la meditación referenciado por Moraes (2019) para el mindfulness en contextos biomédicos. Por lo tanto, de modo contrario, puesto en estos términos se trataría de opciones y usos "cosmologizados" de la meditación.

En este campo, el trabajo de Šksupele (2015) con grupos de Meditación Cristiana en Letonia analizó el "encuentro cultural" entre personas que pertenecen al movimiento y otras que no forman parte de él, pero que, pese a ello, logran intercambios positivos a partir de la espiritualidad y las modalidades de relación con dios. Contando con experiencias previas con otras religiones y en un contexto social general de diversidad, los meditadores aseguran desarrollar una mayor comprensión de sujetos de diferentes procedencias culturales. En este caso, la espiritualidad y la meditación obran como vehículos de una relación que estimula la aceptación, la interlocución y la tolerancia del otro. En una línea similar, otros estudios señalan la cualidad inclusiva de Meditación Cristiana como un movimiento que fomentó desde su inicio el diálogo interreligioso y la inclusión de quienes se adscriben a su práctica al margen de su identidad confesional, razón por la cual se dijo que posee una "identidad religiosa pluralista" (Mermis-Cava, 2009).

A propósito de esta característica, otra investigación sobre Meditación Cristiana en grupos conformados por practicantes de distintas adhesiones cristianas -tales como metodistas, presbiterianos, católicos, etc.- afirmó que allí surge "el dilema de la transgresión de las fronteras institucionales sin amenazar el compromiso denominacional" (Mermis-Cava, 2009, p. 436). En este caso, la concepción pluralista de la meditación descansa en la identificación de un núcleo cristiano compartido con otras religiones que consiste en el silencio asociado al ejercicio contemplativo como denominador común. Precisamente, si bien este aspecto abre la conversación con otras formas de religiosidad, existen rasgos adicionales que apuntan a no tensionar la relación con la propia adscripción cristiana. Entre dichos rasgos cabe mencionar el reconocimiento de la meditación como tradición arcana del cristianismo, como una "forma pura" de oración y, no menos importante, como una acción renovadora de la religión (Mermis-Cava, 2009, p. 445). Por otro lado, existe una arista que resalta el carácter universal de la meditación 
y que en el curso de las reuniones del grupo de meditación en el que participé se hacía particularmente patente en las menciones a referentes religiosos orientales. Esta dimensión ecuménica, junto con las concepciones de la persona sobre las que me detendré luego, forma el primer eje de la dimensión cosmológica de la meditación cristiana.

\section{ECUMENISMO ESPIRITUAL Y EL ORIENTE CRISTIANO}

En los encuentros de los que había participado en el grupo de meditación en el que hice el seguimiento etnográfico ${ }^{6}$, Antonio -quien estaba a cargo de su coordinación- había dado repetidas muestras de una actitud de independencia intelectual respecto a ciertos postulados teológicos de la iglesia, así como de la autoridad eclesiástica en materia del conocimiento de dios. Todo ello había sido fruto de una "evolución" personal a lo largo de una extensa trayectoria de vida como laico. Como me dijo en una de nuestras charlas, sin llegar a ser displicente, siempre ejerció una "toma de distancia" de lo que él mismo definió como la parte "estructural" de la iglesia; ello, afirmaba, "porque me fui liberando de todo ese tipo de... fui evolucionando yo, fui profundizando esto de la palabra, de la figura de Jesús, de la adhesión a él y no a la estructura... Nunca me preocuparon los dogmas ni esas marcas de la iglesia". En resumen, "siempre tuve un pensamiento crítico" y en la Iglesia misma durante los años 70 "era medio rebeldón [i.e. rebelde]". En esa época era empleado de una empresa estatal y, en ese mismo momento, "estaba estudiando ahí en la Facultad de Filosofía y Letras ${ }^{7}$ y para los peronistas era comunista yo... Y en la facultad, como a veces tiraba algunas

\footnotetext{
${ }^{6}$ En este grupo, el promedio de edad estaba por encima de los 40 años, y siempre oscilábamos entre 10 y 15 personas. En general, la asistencia era regular en la mayoría de los asistentes; un segmento inferior, en el orden del $30 \%$, aproximadamente, era variable y se renovaba esporádicamente. En cuanto a su composición, se trataba de gente adulta mayor, como era el caso de Antonio, que coordinaba el grupo desde hacía algunos años. Las mujeres eran mayoría, estando algunas de ellas retiradas del mundo laboral. Un dato para destacar es que algunos de los integrantes habían hecho o estaban haciendo yoga en simultáneo con la meditación. En este apartado y en el siguiente me centraré recurrentemente en la experiencia biográfica de Antonio, puesto que condensa como ninguna de las otras que llegué a conocer aspectos que solo pude hallar fragmentariamente en los trayectos de otras personas. En términos metodológicos y analíticos, esta estrategia narrativa me permitirá seguir una secuencia para tratar los argumentos de este artículo.

${ }^{7}$ Se refiere a la Facultad de Filosofía y Letras de la Universidad de Buenos Aires, un centro académico argentino que, por ese tiempo y al igual que otros ámbitos intelectuales, era visto como un espacio de concentración e intercambio de ideas de izquierda.
} 
cositas de la iglesia, era facho ${ }^{8}$, viste?... En ningún lugar andaba bien [risas]" (Antonio, comunicación personal, junio de 2013).

Su pertenencia a esos dos mundos, dada por las dinámicas políticas del período, parecía repetirse nuevamente en la actualidad, con su práctica activa de la meditación cristiana en la iglesia. Por otro lado, la actividad laboral privada como comerciante de libros primero - en la cual se inició tímidamente trabajando aún como empleado público para complementar un exiguo salario- y luego como trabajador de una editorial católica, le brindaba una posición privilegiada - sumada a una larga experiencia como laico- para observar al catolicismo desde una singular perspectiva. Tal y como veremos, los libros le mostraron el camino a Oriente. Fue esta disposición de autonomía dentro de un universo cosmológico normativo como el católico que, en una ocasión, años atrás y en el marco de una concurrida asistencia de catequistas en La Plata, ciudad de la provincia de Buenos Aires, lo había llevado a ser tildado de "luterano" por el mismísimo exarzobispo Héctor Rubén Aguer?.

En materia de interacción y afectación cosmológica, las relaciones del catolicismo con Oriente fueron estimuladas por vínculos y experiencias personales como por políticas eclesiásticas orientadas al diálogo interreligioso a partir del Concilio Vaticano II, acaecido entre 1962 y $1965^{10}$. En ambos casos surgieron diferentes modos y grados de apertura hacia la alteridad. En esta línea, la creación de los primeros grupos de meditación por el benedictino John Main y la posterior fundación de la Comunidad Mundial para la Meditación Cristiana por su discípulo

\footnotetext{
${ }^{8}$ El término "facho" es una expresión coloquial que alude a una persona conservadora o de derechas en lo político. En el caso referido por Antonio funciona como una adjetivación personal negativa por su lazo con la iglesia católica, la cual para ese entonces era particularmente asociada con el poder a excepción de las líneas de la teología de la liberación.

${ }^{9}$ Aguer ejerció como arzobispo de la diócesis de La Plata entre 2000 y 2018, y tuvo un protagonismo público destacado que le sirvió de medio para divulgar su posición conservadora en terrenos como el de la educación, la sexualidad, el matrimonio, etc. Como férreo opositor a todo lo relativo a la Nueva Era, cuestionó al expresidente Mauricio Macri por abrir el debate sobre el aborto y al actual mandatario Alberto Fernández por la misma razón. Estas críticas a la New Age no son solo individuales, sino que forman parte de un discurso de impugnación más amplio del que se hicieron eco distintos sectores católicos y cristianos (Woodhead, 2011).

${ }^{10}$ Aun en el frente del diálogo interreligioso, hubo religiosos que marcaron su propia impronta personal, tal como lo fue el caso del padre Ismael Quiles (1906-1993) que derivó en la fundación de la Escuela de Estudios Orientales en la Universidad del Salvador en Buenos Aires en 1967 (Álvarez \& Forni, 2018). Por otro lado, la primera estrategia dio origen a actitudes que sedimentaron experiencias y miradas reflexivas y -en no pocas ocasiones- críticas al catolicismo. En esta línea se encuadraron las prácticas de religiosos que tuvieron acercamientos con Oriente como Hugo Makibi Enomiya-Lassalle (1898-1990), Raimon Panikkar (1918-2010), Thomas Merton (1915-1968), John Main (1926-1982), Henri Le Saux (1910-1973), Alan Richard Griffiths (1906-1993), Jules Monchanin (1895-1957) y Willigis Jäger (1925-2020), entre otros.
} 
y continuador Laurence Freeman, fue parte de esta mirada sobre religiosidades orientales que derivó en un movimiento laical de escala global. La presencia de esta y otras expresiones similares en el catolicismo demuestran, al menos, que la soberanía de la institución sobre la ideología religiosa pierde eficacia frente a un universo atomizado de sujetos que desafían los paradigmas de la persona cristiana y, en consecuencia, que la cosmología gana autonomía de la institución.

En el grupo de meditación, el acercamiento a ese horizonte simbólico se hacía notar en múltiples formas. Por ejemplo, las lecturas que Antonio promovía entre quienes íbamos diferían de las que había visto en librerías católicas. Así, autores como Raimon Panikkar, Antonio de Mello o Thích Nhất Hạnh formaban parte de las citas frecuentes que leíamos en los encuentros. En general, este aspecto tenía que ver con que el grupo estaba caracterizado por cierta libertad, tanto en la organización de las reuniones como en relación al material o discusiones que podían proponerse ${ }^{11}$.

En adición, tomando una posición intelectual solidaria con ellos, a partir de su larga experiencia como librero caracterizaba al sujeto que adhería al "rubro católico" del libro como alguien que "o es muy rígido [al punto de ser "fundamentalista"] o le da lo mismo cualquier cosa"; al tiempo que ese mismo lector se mueve en un mercado editorial cuyo "público es pequeño, escaso" (Antonio, comunicación personal, junio de 2015). En este sentido, contaba que su apertura a una literatura algo distinta de lo que dictaba la costumbre como la de de Mello le trajo problemas en los años 90, como lo que le ocurrió una vez con adherentes de la Renovación Carismática. Ellos decían que eso era "satánico". Además, tenían una emisora barrial y aprovechan desde allí para cuestionarlo ácidamente. A raíz de este problema, poco después recibió la visita inesperada del obispo Villalonga. Ambos se conocían bien a causa de los espacios que compartían en los cursos y seminarios en los que Antonio participaba regularmente en la diócesis, de los cuales este prelado era su directo responsable. En esa visita, tal como me la describió (comunicación personal, junio de 2015), mantuvieron esta conversación:

V - ¿Antonio vos tenés libros de Anthony de Mello?

A - Sí.

$\mathrm{V}-$ ¿Y no te convendría sacarlos?

A - No, me parece bárbaro.

\footnotetext{
${ }^{11}$ Esta flexibilidad podía alcanzar incluso a la gestión misma del grupo de meditación. En un par de ocasiones escuché a Antonio convocar voluntades para reemplazarlo en la coordinación, como una forma de distribuir el liderazgo y la responsabilidad en la conducción. Su convocatoria no tuvo éxito y, finalmente, continuó a cargo del funcionamiento colectivo. Wood (2007, p. 93 ss.) estudió una forma de autoridad comparable en un grupo de meditación de Nottinghamshire, Inglaterra.
} 
$\mathrm{V}$ - ¿Vos viste la carta de Ratzinger ${ }^{12} \ldots$ ?

A - Sí, pero pensá que no dice nada concreto... Bueno... hago una cosa, yo lo saco... Pero vos haceme una carta diciéndome que lo tengo que sacar, y que el curso que vos hiciste para los laicos recomendando Sadhana de Anthony de Mello fue un error tuyo.

El libro al que apuntaba Antonio era Sadhana. Un camino de oración (1978), el cual tomaba el nombre del establecimiento que había sido fundado por el mismo de Mello en 1973 en la ciudad de Pune, India: el Sadhana Institute of Pastoral Counselling. Originalmente publicado en inglés con el título de Sadhana: A Way to God y adoptando una base ignaciana ligada a la pertenencia jesuita de su autor, la obra reflexionaba y reunía estrategias de contemplación y meditación pensadas inicialmente para la orientación de guías espirituales. $\mathrm{Cu}$ riosamente, Villalonga había sugerido este material como "soporte" bibliográfico a los responsables del seminario para laicos que le recordaba Antonio con algo de ironía. Él ya había pasado por contradicciones análogas y estaba preparado para lidiar con ellas. Al final, la situación nunca pasó a mayores y de Mello siguió exhibiéndose en las estanterías de su librería.

De hecho, esta literatura le había alentado a escribir sus propias obras. Fue así que publicó un devocionario, una novena, un libro de cuaresma y algunas reflexiones espirituales. Cuando le pregunté si el interés por la escritura tuvo relación con su "alejamiento" de la iglesia dogmática me corrigió y habló de "crecimiento", el cual también relacionó con su llegada a Meditación Cristiana. Se trató, como afirmó, de una "búsqueda de lo amplio... yo venía hacía muchísimos años buscando" (Antonio, comunicación personal, junio de 2015). De acuerdo con su interpretación de las cosas, él nunca se fue de la iglesia:

Nada de lo de la iglesia, ni de lo que yo viví, ni de lo que cuenta la historia en realidad
nada me escandalizó, nunca. Porque me pareció más importante el mensaje de Jesús que
el de los hombres $[. .$.$] Y como siempre tuve una apertura muy grande hacia las otras$
religiones, hacia lo que pensaba el otro, de respetarlo, de ver que cada uno tiene una ri-
queza para ofrecerte... Y yo he ido a charlas de los adventistas [...] he ido a charlas... si
Aguer se entera [risas]... a los luteranos [...] encuentros con bautistas. Con la gente de la
comunidad musulmana he ido también a verlos, me encantaba leer el Corán... Poco con
los budistas, porque tal vez no encontraba [...] Toda cosa que venía del hinduismo... veía
frases [...] Entonces empecé a incursionar en el hinduismo [...] y después encuentro
a Anthony de Mello y me di cuenta que tan equivocado no estaba. Cada cosa que yo leía
de... una frase, un proverbio que veía del hinduismo me despertaba... Me daba como un
vuelo a la libertad a volar, de manera que no me la daban a lo mejor ciertas cosas de

12 Se refiere a la "Notificación sobre los escritos del padre Anthony de Mello S.J." del 24 de junio de 1998 de Joseph Ratzinger, quien, como autoridad responsable de la Congregación para la Doctrina de la Fe, declaraba la incompatibilidad de las afirmaciones de de Mello con las creencias y doctrina de la iglesia católica. 
nuestro paño [el catolicismo]... Lo otro me hacía respirar aires nuevos (Antonio, comunicación personal, junio de 2015).

Su vuelco hacia corrientes alternativas de pensamiento y experiencia religiosa lo llevaron a mundos que le fascinaron y le permitieron ganar en visiones que amplificaron la riqueza cosmológica sin renunciar al catolicismo. La distinción entre la institución y Jesús es central en un relato que destaca por su propósito de exploración y desplazamiento hacia horizontes desconocidos. Como afirmó en una de las jornadas de meditación en las que nos había hecho ver un corto fragmento audiovisual correspondiente a una charla del monje vietnamita Thích Nhất Hạnh, "Jesús era oriental". En una suerte de cruce interreligioso y transcultural, ideas, pensamientos y prácticas provenientes de otras corrientes y tradiciones servían a menudo para entablar un diálogo productivo con Jesús y el Evangelio. De este modo, las reuniones de meditación solían transformarse en una especie de laboratorio espiritual. Allí, la comparación y la búsqueda de similitudes -más que de las diferencias- inspiraban la indagación y experimentación individual junto con una reflexión colectiva, en la que previa o posteriormente a la meditación, los asistentes se animaban libremente a participar. Como sostuvo Versteeg (2006, p. 94), "[1]as tradiciones son deconstruidas y empleadas selectivamente como recursos de significado, por lo cual la experiencia determina la combinación de las fuentes religiosas. En este sentido, la meditación, con su espacio y falta de límite a las intenciones individuales, parece ser la técnica perfecta para una experiencia inclusiva".

En definitiva, esta suerte de imaginación cosmológica opera sobre la imagen de Jesús como un significante en disputa que asegura la permanencia de un lazo de unión con el catolicismo. Sin embargo, concomitantemente, también ilustra un grado importante de autonomía para su resignificación. Como corolario, habría contestación hacia lo que se entiende como institucional, pero poco o nada a lo que es propio de la materia cosmológica. La incursión de la institución sobre las imágenes es objeto de disputa cuando despliega su papel regulador. En otro orden, la persistencia de una mirada encantada hacia el mundo, aun en el marco de instituciones ancestrales y eventualmente contestadas, estimula procesos de invención e imaginación que derivan en ontologías de las cuales variantes espirituales como la meditación cristiana pueden ser una muestra. En el siguiente apartado me detendré en las características del sujeto que está detrás de tales acciones de imaginación cosmológica. 


\section{UN RETORNO AL SUJETO}

Antonio tenía una visión muy clara de lo que significaba la espiritualidad y cómo se podía distinguir de otras formas de religiosidad que parecían disputarle su lugar. Así, por ejemplo, expresiones que se proclamaban como tales como la que encarnaba Claudio María Domínguez (véase Semán \& Battaglia, 2012) eran más bien casos de una "autoayuda" donde "está visto el hombre independiente de la figura de dios, es el hombre por el hombre mismo en cuanto a su camino" (comunicación personal, noviembre de 2014). En la actualidad, proseguía Antonio, esta misma línea incorporó la meditación como una vía que permitiría llevar a la persona a un estado de "bienestar general". Al contrario de cómo introduce la meditación esta vertiente que se identifica con la autoayuda, Antonio -como muchos otros meditadores- sostiene que "esto es una cosa que arranca desde los primeros siglos del cristianismo". Para él, lo mismo ocurría con la oración, los místicos y la espiritualidad. Esta última, en la experiencia de la Iglesia al menos, había estado asociada a la aparición de movimientos religiosos. Así tuvo lugar la espiritualidad de San Ignacio, de San Francisco, de Santo Domingo de Guzmán, etc. Por esta razón, me aclaraba con una certeza de quien mira todo en perspectiva, la gente tiende a identificar la espiritualidad con un movimiento religioso.

Continuando con esta alocución sobre la espiritualidad católica en particular, y como en un tono de profunda reflexión dijo, "yo creo que a la iglesia le está faltando mirar al hombre". Dicho de otro modo, "ver al hombre como que está transcurriendo un momento de la historia... Y que no es que al hombre hay que meterlo adentro de nuestra teología... Yo creo que nuestra respuesta espiritual es ver cómo camina el hombre por el siglo XXI. Miramos más la teología, y se la queremos imponer al hombre, cuando [él] nos puede enseñar a que nosotros le retransmitamos el mensaje [y] que lo pueda leer" (comunicación personal, noviembre de 2014). Su idea es que la Iglesia puede sustituir al campo "secular" en su rol de proveedor de espiritualidad a un sujeto contemporáneo que la busca inexorablemente y lo hace, a su entender, en un ámbito que ella misma podría cubrir; es decir, la Nueva Era -a la que "no hay que mirar como si fuera una palabra tan espantosa"- representa una expresión espiritual a la que la Iglesia debería prestar más atención, puesto que "el hombre va en busca de eso".

Sin embargo, Antonio resaltaba una diferencia sustancial entre aquella y la que proponía la meditación cristiana; para él, la Nueva Era "es una espiritualidad desprovista de dios". De parte de él, había aquí una apropiación emic de una noción de espiritualidad que surgía en el marco de una religión para señalar 
diferentes formas de vivir y experimentar la fe. Una acción que él y otros meditadores hacían sin desmarcarse del todo de los deícticos que definían su propia identidad como católicos. Por lo tanto, la espiritualidad era en lo cosmológico solidaria con la religión y, de hecho, podría incluso decirse que consistía en un sutil desplazamiento ontológico de la misma religiosidad -católica- que cuestionaba. Adoptando una posición que criticó de la iglesia, Antonio entiende que "el hombre de hoy no quiere que lo empaqueten", aludiendo a que la iglesia inmediatamente lo fuerza a "rituales, dogmas y estructuras [mientras que aquél] vive en una libertad y en una espiritualidad completamente distinta" (comunicación personal, noviembre de 2014). Estas nociones y percepciones generales sobre el sujeto fueron surgiendo de manera dispersa y de boca de los meditadores a lo largo de reuniones, lecturas y conversaciones. Se mostraron núcleos concretos que se irían haciendo cada vez más claros en función del avance personal en la práctica de la meditación; a saber, el espacio interior, la mística envuelta en la experiencia meditativa y el estado ontológico resultante de su práctica. Esta última, debe notarse, era visualizada como una ruta con obstáculos. Sin embargo, sus frutos aguardaban a quien perseverase en la senda. Veamos entonces el primero de estos rasgos que dibujaba los contornos de una cosmología sui generis.

\section{El trabajo interior}

La meditación cristiana se lleva a cabo mediante la repetición mental continua de un "mantra" -o "palabra sagrada" como se le dice en Oración Centrante (Bourgeault, 2009; Keating, 1986, 1998a, 1998b)-. Si bien se aceptan otras alternativas, para el mantra sugieren pronunciar el término arameo de maranata que significa "ven a mi Señor". Esta palabra se asume que es sagrada, que está en otro idioma y, por lo tanto, impide la distracción del estado consciente de quien medita e, igualmente relevante, posee un ritmo silábico uniforme; es decir, una musicalidad que refuerza la focalización. Sosteniendo una respiración lenta y profunda, la atención del meditador se dirige por completo a esta palabra para eludir cualquier idea o pensamiento que pueda distraer la mente. La misión central del acto de meditar es lograr colocar al sujeto en presencia de dios a través de la preparación previa de un espacio sagrado interno que funciona como un templo. La genealogía de esta tecnología, si bien se ancla inicialmente en la experiencia del fundador de Meditación Cristiana John Main a partir de su aprendizaje con Swami Satyananda en Malasia, más tarde se termina referenciando y cultivando en la patrística; en especial, en la obra de Juan Casiano -360 d.C. - ca. 435 d.C.--, uno de los 
llamados Padres de la Iglesia ${ }^{13}$. Después de un primer intento fallido de trasladar la forma de meditación oriental que había aprendido al monasterio benedictino de Ealin de Londres al que pertenecía, Main encaró el estudio de los textos patrísticos hallando en Casiano el argumento para conectar la meditación oriental con la cristiana (Black, 2000).

La recitación interior y silenciosa del mantra era compatible con el mandato de la "oración permanente" (unceasing prayer) propuesta por Casiano, para quien el rezo sin interrupción constituía el único medio para asegurar al monje la llegada al Reino. De ahí que en Meditación Cristiana, al igual que en otras expresiones como en Oración Centrante, la referencia al pasado remoto dio legitimidad a un ejercicio espiritual que en algunos círculos católicos fue visto con recelo; en especial, en los casos que los meditadores veían similitudes con linajes orienta1 les ${ }^{14}$. En idéntica dirección, la inclusión de la espiritualidad mística medieval y barroca amplió el espectro de los casos que corroboraban que la meditación era parte de una tradición cristiana ancestral ${ }^{15}$. La narrativa institucional sobre el pasado remoto de la meditación ofrece a los meditadores, portadores en su mayoría de un saber fragmentario de ese pasado al que vulgarmente muchas veces se

\footnotetext{
${ }^{13}$ Casiano pasó más de diez años entre los monjes egipcios, de quienes heredó enseñanzas y costumbres de una forma de vida monástica que luego plasmó en sus dos obras magnas: Instituciones Cenobiticas y Colaciones. La primera de ellas dirigida a la organización del monasterio y la segunda al cuidado de la vida espiritual interior de quien renuncia al mundo. Pese a su defensa de la vida eremítica por considerarla la vía más perfecta para llegar a dios, no descartaba la experiencia comunitaria (cenobítica) previa a fin de educar, a través de la ascesis, al futuro ermitaño. Su trabajo constituyó una inspiración teológica nodal para el proyecto monástico de san Benito de Nursia (480 d.C. -547 d.C.), quien fue uno de los principales arquitectos del monacato occidental.

${ }^{14}$ La primera y más contundente reacción institucional provino en 1989 de Joseph Ratzinger, a través de su "Carta a los Obispos de la Iglesia Católica sobre Algunos Aspectos de la Meditación Cristiana". Allí alertó sobre los "riesgos y errores de mezclar la meditación cristiana con la no cristiana". Esta declaración, además de reconocer la divulgación de formas orientales de meditación en el laicado, mostraba las contradicciones o al menos las limitaciones a las que la iglesia quedaba sometida a partir de la declaración conciliar de Nostra Aetate (1965) sobre el Diálogo Interreligioso. Años más tarde, una nueva declaración del mismo cardenal en 2000 -Dominus Iesus - reconoció el valor de y el respeto por las religiones no católicas, al tiempo que afirmó la vía salvífica de la iglesia como la única, lo cual dejaba a los no católicos en una "situación gravemente deficitaria" (véase, du Boulay, 2003).

${ }^{15}$ Estas referencias históricas recurrentes se muestran en la literatura que se menciona en ocasiones en los encuentros de meditación, pero también en cursos de formación, reuniones, conferencias, etc.; en suma, forma parte de un relato consistente que apunta a la construcción de una tradición espiritual. Así, textos como Los Dichos de los Padres del Desierto, Filocalia, los Relatos de un peregrino ruso a su Padre Espiritual, La Nube del no Saber y otros tantos materiales producidos por personalidades emblemáticas de la mística como San Juan de la Cruz, Teresa de Ávila, Sor Juana Inés de la Cruz, etc., se suman al panteón de eminencias que certifican la permanencia de la meditación (cf. Marchesi Ullastres, 2016).
} 
refiere como "historias de los santos", una clave hermenéutica para interpretar y dar sentido a las experiencias propias y ajenas.

Este relato fundacional, que marcaba el carácter originario de la meditación y subrayaba el olvido posterior en el que había caído como parte de las prácticas cotidianas de la Iglesia, disolvía eficazmente los imaginarios que la vinculan solo con la Nueva Era u Oriente. "Yo no sabía que esto [la meditación] 'también' existía en la iglesia" (Brenda, comunicación personal, marzo de 2016), señalaba una adherente que mostraba sorpresa frente a algo que conocía de otros espacios religiosos (para situaciones idénticas, véase Mermis-Cava, 2009, p. 446). Ahora, si bien las menciones a Casiano y a otras figuras consagradas de la Iglesia forman parte de la discursividad escrita y oral de la organización -junto a otras personalidades asociadas con religiones orientales-, no hay en los meditadores un interés particular en intelectualizar la meditación. Las lecturas que solíamos escuchar operaban más a modo de un "listado de sugerencias" que precisaba o enriquecía el conocimiento - mayor o menor- que cada uno tenía.

Por lo tanto, debe notarse que, en general, persiste un énfasis sobre la meditación como experiencia, exploración y realización en sí y para sí mismo más que su racionalización teológica. Es decir, a dios no se llega por la razón sino por la experiencia. El mantra apunta a silenciar la primera y a abrir los portales para la segunda. La experiencia da lugar a un proceso de aprendizaje sobre la práctica meditativa y aun sobre el ser mismo que aprende sobre sí, en tanto que objeto al que se dirige el trabajo silencioso de la meditación. Esta no se trata de una acción individual o voluntarista que depende de una pedagogía autogestionada para su aprendizaje sino, más bien, de un ensamblaje ritual en el que en cada encuentro grupal se socializan preguntas, lecturas, comentarios y vivencias que potencialmente pueden favorecer el proceso de recomposición cosmológica y ontológica. Al respecto de esto último, una practicante con una historia católica por detrás que había pasado por el budismo y resaltaba el valor del silencio colectivo en la meditación como fuerza efectiva para la transformación individual, decía que a dios hay que "buscarlo interiormente" (Esther, comunicación personal, octubre de 2013). El trato cada vez más asiduo con la meditación y posterior incorporación había modificado su práctica del rezo convencional. Este nuevo ejercicio de oración basado en el silencio dio protagonismo a una esfera íntima que se percibía ahora de otra manera.

En la óptica de la oración centrante del padre Keating (1986) y siguiendo una antropología en la que dios es constituyente del sujeto, habría una revelación interior que provendría de la sustitución del "falso yo" por parte del "verdadero 
yo". En esta línea, con un enfoque "psicoespiritual" en sintonía con la propuesta de Keating, la carmelita española Marchesi Ullastres (2018) -que brindó charlas y retiros espirituales en Argentina y en otros países de la región- habla de la "sanación del inconsciente". Esta perspectiva sugiere que se debe primero "integrar" el yo que se encuentra en un estado de escisión para luego poder trascenderlo (Marchesi Ullastres, 2018). En suma, la meditación como la oración centrante promueve un movimiento hacia el interior de la persona. Como nos recordó una vez Antonio tomando unas palabras de Main al término de una meditación, "el viaje de la meditación es un peregrinaje a nuestro propio corazón, el lugar más sagrado donde habita Cristo. La meditación es descubrir "la vida del Espíritu de Jesús dentro de nuestro corazón humano"”. Este trabajo interior que viene con la meditación implica una relación singular con lo numinoso, sobre la que me detendré a continuación.

\section{Intimidad mística}

Como vimos, en la narrativa sobre el origen de la meditación cristiana hay dos aspectos que remiten, por un lado, a una fuente mítica oriental dada por la experiencia de aprendizaje de la meditación de Main a través del monje hindú Swami Satyananda entre 1955 y 1956; y, por otro lado, al tiempo remoto del cristianismo primitivo en el que Casiano se refería a la meditación en sus famosas Conferencias como la "contemplación divina". En este sentido, la adopción de la meditación como práctica ritual cotidiana replanteó la relación de la persona con lo numinoso. En este contrato cobra protagonismo la gestión individual de la experiencia religiosa. Por ejemplo, Antonio había declarado que "estaba como en una búsqueda... una búsqueda muy muy grande". De este modo, se lanzó a un camino que, sin abandonar el catolicismo, lo condujo a explorar saberes distintos nutridos de expectativas renovadas. En su caso, la búsqueda sugiere tanto una idea de conocimiento en libertad como una de interioridad. Otras personas con las que había conversado llegaron a la meditación un poco fortuitamente y con algo de curiosidad. Incluso estaban quienes habían hecho yoga, y la meditación les concedía una nueva modalidad de habitar el catolicismo y descubrir dimensiones de su mundo interior que eran menos visibles con la oración ordinaria. Esta misma motivación estuvo en Antonio.

El movimiento del Vaticano II me pegó muy fuerte, yo era un tipo muy rígido en mi estructura mental... Pasó un tiempo más he hice el curso de Profesor de Ciencias Religiosas [...] Cuando asumo un mayor compromiso con eso que empiezo a dar las charlas de catequesis, me meto en un movimiento de pastoral para adolescentes que lo daban los 
maristas y en ese instituto de pastoral tomo conocimiento y hago una cantidad grande de cursos de teología de la liberación... y ahí conozco a Leonardo Boff [...] Después seguí con los dominicos. Con los dominicos hice cursos de biblia... (Antonio, comunicación personal, junio de 2013).

Estas inquietudes que lo guiaron por senderos sinuosos del catolicismo también lo llevaron fuera de él. Su mirada hacia Oriente, manifiesta en los autores que leía y nos traía con frecuencia a las reuniones de meditación, la había advertido en intercambios con personas que meditaban en otros grupos, en conferencias del movimiento de Meditación Cristiana y en la literatura que promovía. En este sentido, la relativización de lo católico y de la necesidad de pertenecer a esta denominación para participar de las meditaciones hacía de ellos un grupo plural. Así, a partir de su estudio sobre un grupo de meditación de católicos, Versteeg (2006, p. 85) sostiene que "la experiencia individual y el contexto tradicional de la experiencia se separaron; la experiencia ya no es más definida y evaluada en este contexto, sino potencialmente delineada por medio de diferentes influencias culturales y religiosas siguiendo estilos de vida y preferencias individuales". En suma, en una sociedad de creciente diversidad religiosa, los meditadores se presentan como aquello que Wuthnow (2005) llamó "cristianos inclusivos".

Junto a este pluralismo de ideas y experiencias, la relación con lo numinoso expresa un vínculo con la meditación que pone en el centro de la discusión su diferencia con la oración convencional. En palabras de Raúl, otro meditador que proviene del movimiento carismático, "la fe nuestra es muy primaria, muy de niños... El padrenuestro, el avemaría... Entonces la oración [se refiere a la meditación cristiana] nos da una cierta madurez como en el sentido de compenetrarnos con nosotros mismos y con Jesús, y eso es fundamental". Raúl toma a la meditación como una forma más de oración, aunque superior en algunos sentidos a la que está acostumbrado, a la cual otorga una jerarquía mayor.

En el caso nuestro de meditación cristiana, te hace compenetrar mucho en las decisiones que Jesús te da a vos, a cada uno de nosotros. Entonces ahí es donde vos te das cuenta perfectamente qué es lo que quiere hacer Cristo con vos. Es decir, te orienta. Sos una herramienta de él, te va a orientar. Por eso la meditación te hace a vos estar en silencio media hora para que te dejes llevar; te liberes internamente de tu persona, es la misión del método de meditación (Raúl, comunicación personal, septiembre de 2016).

La meditación se advierte como una variación de la oración ordinaria que realizan como católicos y no como su opuesto. Sin embargo, incorpora un conjunto de elementos físicos - postura, respiración, repetición interior de un mantra, etc.- que difiere de la forma consagrada del rezo. Se entiende que facilita un grado de intimidad con dios y con uno mismo que es superador. La dimensión corporal permite concluir el ejercicio meditativo con una sensación diferente a la 
que se asocia con la oración, siendo la primera considerada como una innovación respecto de la segunda y novedosa pese a haber sido redescubierta desde el pasado cristiano. Como dijo Raúl en una ocasión, "Jesús meditaba como nosotros". Un aspecto adicional que refuerza la intimidad que recrea la meditación es el hecho de tener espacios domésticos para realizarla de forma más o menos regular en función de un balance entre la actividad laboral y la hogareña. Los más entusiastas del grupo, aquellos que Ammerman (2014) engloba en el segmento "espiritualmente comprometido" -y que aquí eran la mayoría-, declaraban dedicar uno o dos momentos diarios de diez a treinta minutos para meditar. Eso podía hacerse en la casa tanto como en el transporte público en los casos más extremos. Quienes no podían disponer de esos espacios de meditación, lo hacían más esporádicamente o, a lo sumo, dependían de la meditación semanal realizada grupalmente. En general, se trata de una práctica individual y solo dos de las parejas de adultos mayores que asistían al grupo decían hacerla juntos diariamente. La percepción extendida sobre el bienestar resultante de su ejecución, que es la tercera condición que caracteriza la noción de persona, será tratada en el ítem siguiente.

\section{Estar bien, sentirse mejor}

De las numerosas veces que escuché a Antonio exponer y explicar la práctica de la meditación a quienes se sumaban por primera vez al grupo, fue la simplicidad de la técnica y su efectividad para lograr la paz interior "en Cristo" el rasgo que más destacó. Junto a esta cualidad, la breve y concisa presentación que hacía para los recién llegados solía detenerse, además, en la responsabilidad personal en la gestión y el monitoreo de la meditación, la cual era recomendable practicar como mínimo una vez al día; es decir, el cómo hacerla, así como el dónde y en qué momento llevarla a cabo. Asimismo, al principio de simplicidad se sumaba el de la agencia del meditador en su realización. Aquí la meditación aparecía como una acción que no exigía mediaciones -jerarquizadas o especializadas- de ningún tipo, una vez incorporados sus rudimentos. La descentralización del control ritual sobre su práctica revalorizaba los tiempos y espacios cotidianos del meditador como nuevos ámbitos de sacralidad. Un tercer aspecto que oía con frecuencia en las introducciones a la meditación era su promesa de un estado de cierto bienestar, el cual sería corolario de todo lo demás: "después de meditar te vas a sentir mejor", se decía, y era algo que luego confirmaba con el resto de las personas que meditaban. En efecto, parte de ese juramento parecía consumarse al concluir la meditación colectiva de cada reunión. En esos momentos, la salida lánguida del silencio al que nos sometía el mantra que cada uno recitaba para 
sí en su interior reiniciaba el trato mutuo en una atmósfera de calma, a un ritmo social más lento pero receptivo y sensible para con el resto de los compañeros.

El bienestar se asocia con el estado ontológico genérico de quien medita, más que con el apaciguamiento del dolor físico o el mejoramiento de una enfermedad. A diferencia de lo que puede ser la oración, en ocasiones recitada para el bien de otro, la meditación es ciertamente para uno y desde uno. Como nos señaló Antonio más de una vez, "la oración es para mí". La práctica de esta tecnología se materializa en disposiciones y sensibilidades cuya adecuada autogestión por parte del sujeto garantiza un cambio en el ser y en su estar en el mundo. Allí está la clave para el bienestar personal, el cual ya ha sido estudiado para otras tecnologías tales como el yoga (D’Angelo, 2013; Santillana Vallejo, 2018), la medicina ayurveda (Freidin et ál., 2013), la "práctica de purificación" o kriya en El Arte de Vivir (D'Angelo, 2014; Viotti, 2018), "elevación espiritual” en el espiritismo y entonación de daimoku para el budismo nichiren (Algranti \& Gancedo, 2015), entre otros. Para Várguez Pasos (2015, p. 165) "los factores que constituyen el bienestar subjetivo [...] son internos al individuo; no existen fuera de él, pues dependen de su percepción del mundo y de la vida cotidiana y de las interrelaciones que establece con los demás en tiempos y espacios determinados". Por supuesto, el éxito definitivo de la meditación cristiana consiste en prolongar los efectos, estados y sensaciones que provoca en los meditadores más allá del acto ritual en sí. Un aspecto que suele resaltarse para garantizar su eficacia está ligado con la percepción de la temporalidad del sujeto.

En este sentido, se coloca al aquí y ahora como preocupación, por lo cual el foco sobre el presente que orbita la meditación es también un rasgo distintivo. Antonio tenía una frase que repetía con asiduidad: "el pasado ya fue, y el futuro todavía no llegó". De acuerdo con su visión, buena parte de nuestro dolor proviene de los malos recuerdos, incertidumbres y temores que despierta lo que todavía no sucedió o aun de lo que puede llegar a pasar. Por esa razón, la propuesta que siempre nos hacía era vivir y ocuparse de lo actual como una de las cuestiones más importantes; "dios es ahora", replicaba con firmeza. El valor de la contemporaneidad asociada a la vida de la persona es una expresión de la inmanencia encantada a la que conduce la meditación.

Precisamente, en una de las charlas que brindó el hermano David SteindRast de Grateful Living en Buenos Aires en 2013 con motivo de la exposición de uno de sus libros, instó a un auditorio de unas ciento cincuenta personas a "valorar el tiempo presente". Como afirmó entonces, "dios se nos da ya". De modo que el referente de la meditación no es el pasado ni el futuro, sino el presente. Este monje sintetizó su fórmula como stop, observe, go -"detente, observa y avanza"-. Esta 
era su recomendación para salir del flujo acelerado de la vida cotidiana y encontrarse con dios, y garantizar el efecto místico y el bienestar ontológico de la meditación. Asimismo, su práctica de "la gratitud" - es decir, el agradecer como una conducta existencial- emplaza al sujeto en una comunidad y en el orden de las relaciones entre sus miembros, por lo cual enfatizaba una intersubjetividad más que una individualidad, que era lo que en principio podría deducirse de la meditación como terapéutica del alma.

Con un sentido análogo, el mismo Antonio había dicho en una oportunidad que si uno estaba bien, los otros habrían de estarlo con uno mismo. Por otro lado, la noción de "servicio contemplativo" de Keating (1998b), así como el peso depositado sobre el grupo orante (Marchesi Ullastres, 2018) o meditante (Freeman, 2013), apuntan igualmente a situar al meditador en un conglomerado social donde el "bienestar" deviene en un bien compartido ${ }^{16}$. Puesto en otros términos, la meditación no desmantela el imaginario mítico de la comunidad cristiana e instala al individuo en dicho contexto, donde el beneficio derivado de la acción meditativa es también un capital en circulación y distribución.

\section{PALABRAS FINALES}

En este artículo analicé la dimensión cosmológica de la meditación cristiana, la cual conceptualicé como parte de un movimiento contemplativo heteróclito más amplio que inició en el período que rodeó al Vaticano II. Con impacto en el laicado y el espacio secular, este giro contemplativo resultó ser impulsado mayormente por actores monásticos y se cristalizó en una constelación de organizaciones religiosas de las que forma parte Meditación Cristiana Argentina, como filial local adherida a la World Community for Christian Meditation. Estas manifestaciones hicieron de la oración contemplativa y de la meditación las tecnologías centrales sobre las cuales se montaron cosmologías inspiradas en recuperaciones reflexivas del pasado patrístico y místico. En ocasiones, y en distinto grado, ese montaje involucró el tendido de puentes con Oriente. Precisamente, para Main (2014), el éxito del encuentro espiritual entre Oriente y Occidente debía materializarse en el plano de la meditación.

\footnotetext{
${ }^{16}$ Wood (2007, p. 95) habla de un "sentido de comunalidad" para describir un fenómeno parecido en un grupo de meditadores que advierten los efectos de una "experiencia común". En efecto, "[e]n el grupo de meditación había un sentido de comunalidad que no solo habilitaba la ritualización sino también facilitaba el sentido de que el ritual había transformado a los participantes, aunque en diferentes formas" (Wood, 2007, p. 95).
} 
En este sentido, el estudio de la cosmología expresada en la práctica meditativa reveló un matiz ecuménico que reposa en el intercambio ontológico entre mundos y que, pese a corresponderse con universos religiosos disímiles, encontraban un punto de contacto en la unión mística con lo numinoso lograda en el ritual de la meditación. Vimos que este camino implicó cierto grado de confrontación con posiciones conservadoras y reacias a la búsqueda de esas similitudes. Esta posición de diálogo con otras religiones, en especial de origen oriental, evidenció aspectos críticos concomitantes hacia la Iglesia que no se reducían a la oración canónica con la que la meditación venía a competir. Notablemente, al concebir a los primeros cristianos como meditadores, no solo se adjudica un tono de autenticidad y ancestralidad a una acción ritual -vista aún por algunos con recelo por considerarla propia de la Nueva Era- sino que, también, este proceso de construcción del pasado deja a Jesús y a dios en el centro de la escena. Por lo tanto, desde lo simbólico, la prevalencia de una centralidad teísta en la meditación valoriza la dimensión trascendente en lo cosmológico.

En adición a este primer eje ligado al ecumenismo de la meditación, un segundo eje cosmológico se advierte en la noción de persona que la acompaña. Esta arista muestra el carácter inmanente de la práctica meditativa; es decir, la meditación es parte del mundo subjetivo, emocional y espiritual del ser. Aquí destaqué su relación con el espacio interior. En este plano la práctica individual -doméstica- y colectiva -en el grupo de meditación-, junto a la capacidad de penetrar la esfera cotidiana de los meditadores, le otorga una mundanidad que la hace un instrumento poderoso de transformación personal. Esto último es así, al menos, en la percepción de las personas que dijeron practicarla luego de un cierto período de prueba. La apertura de esta esfera interna es un sitio de unión con lo divino, además de serlo con uno mismo. Por lo tanto, la realización de la meditación en cualquier tiempo y espacio privado es igualmente una llamada a su sacralización a partir de la relación de intimidad que genera con lo numinoso. Finalmente, un tercer componente de esta persona cosmologizada es lo que percibe como la retribución ontológica que viene con la meditación.

Esta característica la aproxima al sentido de bienestar en tecnologías parecidas como el yoga, el reiki, etc. Aquí, la sensación de sentirse bien anuda trascendencia e inmanencia, según la cual el mundo secular y sus problemas diarios sobre el sujeto son parte de la ecuación que lo define. La meditación entonces no es una técnica, sino un estado del ser en el mundo. Ella desarrolla una espiritualidad centrada y orientada hacia lo divino, marcada por el foco en el presente y el bienestar de la persona que participa de tejidos sociales más amplios. Recurre para eso a un criterio de accesibilidad y simplicidad que se manifiesta en la per- 
formance ritual, la cual está solo moderadamente mediada por terceros y cuenta con un acompañamiento grupal igualmente autogestionado. La mirada crítica sobre la liturgia tradicional que aparece entre algunos adherentes y la tensión para con ciertos dogmatismos eclesiales vistos como sinónimos de inmutabilidad, conviven con la invención en el plano de la ideología religiosa. La resultante es una permanencia institucional con disensos, en especial, en materia ritual y cosmológica por lo cual están abiertas al juego de la imaginación simbólica. Así, la incorporación de la meditación como una opción novedosa y ciertamente auténtica, exhibe una sensibilidad contemplativa que se seculariza para su aplicación en el mejoramiento de la vida cotidiana.

\section{BIBLIOGRAFÍA}

Algranti, M., \& Gancedo, M. (2015). El bienestar de las periferias: sanación y sacralidad en dos religiones heterodoxas de la ciudad de Buenos Aires. Ciencias Sociales y Religión / Ciencias Sociais e Religião, (22), 136-155. https://doi.org/10.22456/1982-2650.55615

Álvarez, M., \& Forni, P. (2018). Orientalismo conciliar: el padre Quiles y la creación de la Escuela de Estudios Orientales de la Universidad del Salvador. Estudios de Asia y África, 53(2), 441-468. https://doi.org/10.24201/eaa.v0i0.2408

Alves, D. (2004). Seres de Sonho: percursos religiosos e práticas espirituais num centro budista ao sul do Brasil [Tesis de maestría, Universidade Federal do Rio Grande do Sul]. LUME - Repositório Digital da UFRGS. https://lume.ufrgs.br/bitstream/handle/10183/3733/000403679.pdf

Ammerman, N. T. (2014). Sacred Stories, Spiritual Tribes. Finding Religion in Everyday Life. Oxford University Press. https://doi.org/10.1093/acprof:oso/9780199896448.001.0001

Black, J. (2000). Main, John 1926-1982. British Benedictine pioneer in disseminating Christian meditation. En W. Johnston (ed.), Encyclopedia of Monasticism (pp. 807-808). Routledge.

Bourgeault, C. (2009). Centering prayer and the attention of the heart. Crosscurrents, 59(1), 15-27. https://doi.org/10.1111/j.1939-3881.2009.00057.x

Carini, C. (2009). Estructuración ritual del cuerpo, la experiencia y la intersubjetividad en la práctica del budismo zen Argentino. Religião e Sociedade, 29(1), 62-94. https://doi.org/10.1590/S0100-85872009000100004

Carini, C. (2012). Etnografia del budismo zen argentino: Rituales, cosmovisión e identidad [Tesis de doctorado, Universidad Nacional de La Plata]. SEDICI - Repositorio Institucional de la UNLP. http://sedici.unlp.edu.ar/bitstream/handle/10915/35194/Documento_completo.pdf

Carini, C. (2016). Budas en movimiento: la práctica de la danza y el yoga tibetano en una comunidad vajrayana argentina. Religare, 13(2), 321-347.

Cullingan, K., Meadow, M., \& Chowning, D. (1994). Purifying the Heart: Buddhist Insight Meditation for Christians. Crossroad.

D’Angelo, A. (2013). Tendiendo puentes: La apropiación terapéutica del yoga ante la dimensión emocional de los padecimientos. Revista Brasileira de Sociologia da Emoção, 12(34), 321-360. 
D’Angelo, A. (2014). Temblores y otras manifestaciones de la energía. La técnica del sudarshan kriya de El Arte de Vivir. Cultura y Religión, 8(2), 148-165.

D’Angelo, A. (2018). Tecnologías de autorregulación: apropiaciones psi de las técnicas zazen y vipassana de meditación. Avá, (32), 109-129. https://doi.org/10.2307/j.ctvscxt08.21

du Boulay, S. (2003). Truth beyond Division: Eastern Meditation and Western Christianity. En A. Ivereigh (ed.), Unfinished Journey. The Church 40 Years after Vatican II (pp. 257-271). Continuum.

Duerr, M. (2004). The contemplative organization. Journal of Organizational Change, 17(1), 43-61. https://doi.org/10.1108/09534810410511297

Foucault, M. (1991), Tecnologías del Yo y otros textos afines. Paidós.

Foucault, M. (2001). La hermenéutica del sujeto. Curso en el Collège de France (1981-1982). Fondo de Cultura Económica.

Frederick, T., \& White, K. (2015). Mindfulness, Christian Devotion Meditation, surrender, and worry. Mental Health, Religion \& Culture, 18(10), 850-858. https://doi.org/10.1080/13674676.2015.1107892

Freeman, L. (2009). The Selfless Self. Canterbury Press.

Freeman, L. (2013). A Perl of great price. Sharing the gift of meditation by starting a group. Medio Media.

Freidin, B., Ballesteros, M., \& Echeconea, M. (2013). Documentos de Trabajo, (65). http://biblioteca.clacso.edu.ar/Argentina/iigg-uba/20130618055151/dt65.pdf

Gracia, A. (2018). Curación, cuerpo y emociones en la "Llave Mariana": un abordaje antropológico. Religião e Sociedade, 38(1), 136-158. http://dx.doi.org/10.1590/0100-85872018v38n1cap06

Hwang, P. (2018). Mindful Awareness as a Method of Christian Scripture Meditation among Empathic Korean Mothers in South Korea. Christian Education Journal: Research on Educational Ministry, 15(2), 224-242. https://doi.org/10.1177/0739891318778858

Keating, T. (1986). Open Mind, Open Hear. The Contemplative Dimension of the Gospel. Continuum.

Keating, T. (1998a). The Method of Centering Prayer. En G. Reininger (ed.), Centering Prayer in Daily Life and Ministry (pp. 129-135). Continuum.

Keating, T. (1998b). The Practice of Attention/Intention. En G. Reininger (ed.), Centering Prayer in Daily Life and Ministry (pp. 13-19). Continuum.

Kemp, D. (2004). The Christaquarians? A Sociology of Christians in the New Age. En J. R. Lewis (ed.), The Encyclopedic Sourcebook of New Age Religions (pp. 95-110). Prometheus Books. https://doi.org/10.3366/swc.2001.7.1.95

Ludueña, G. A. (2014). Ritual, narrativa e imaginación religiosa descentrada en espiritualidades católicas contemporáneas. Una mirada desde la periferia. Miríada. Investigación en Ciencias Sociales, 6(10), 89-114.

Ludueña, G. A. (2017). A worldly monasticism. New Catholic spiritualities and secularisation of monastic culture in Latin America. En I. Jonveaux \& S. Palmisano (eds.), Monasticism in Modern Times (pp. 137-153). Routledge.

Ludueña, G. A. (2018). Meditación en el catolicismo contemporáneo. En R. Blancarte (ed.), Diccionario de Religiones en América Latina (pp. 362-367). Fondo de Cultura Económica. 
Main, J. (2006). Monastery Without Walls. Canterbury Press.

Main, J. (2014). Word into Silence: A Manual for Christian Meditation. Canterbury Press.

Marchesi Ullastres, P. (2016). Sanados por el amor. A la luz de nuestros Místicos y de la propia experiencia. Fontes.

Marchesi Ullastres, P. (2018). Un viaje al hondón del ser. Psicoespiritualidad. Fontes.

Mermis-Cava, J. (2009). An Anchor and a Sail: Christian Meditation as the Mechanism for a Pluralist Religious Identity. Sociology of Religion, 70(4), 432-453. https://doi.org/10.1093/socrel/srp064

Monteros Gutiérrez, M. E. (2018). "Sana tu Alma”: La conformación y el sostenimiento de un grupo de meditación para una sanación mental, física y espiritual de tipo autonómica en la ciudad de Zárate (Buenos Aires) (Tesis de licenciatura, Universidad Nacional de San Martín). Repositorio Institucional de la Universidad Nacional de San Martín. https://ri.unsam.edu.ar/bitstream/handle/123456789/1133/TLIC_IDAES_2018_MGME.pdf

Moraes, M. R. C. (2014). Autocuidado e gestão de si: Hábitos saudáveis na mídia impressa semanal. [Tesis de doctorado, Universidade de São Paulo]. Biblioteca Digital USP. https://teses.usp.br/teses/disponiveis/8/8132/tde-23012015-182017/publico/2014_MariaReginaCarielloMoraes_VOrig.pdf

Moraes, M. R. C. (2019). O desencantamento da meditação: da união mística ao fitness cerebral. Religião e Sociedade, 39(1), 224-248. http://dx.doi.org/10.1590/010085872019v39n1cap10

Olmos Álvarez, A. (2015). "Venid a mi todos los afligidos". Salud, enfermedad y rituales de sanación en el movimiento católico carismático del padre Ignacio. Ciencias Sociales y Religión / Ciências Sociais e Religião, (22), 52-70. https://doi.org/10.22456/19822650.54690

Otto, R. (1980). Lo Santa Lo Racional y lo Irracional en la Idea de Dios. Alianza.

Partridge, C. (2004). The Re-Enchantment of the West. Alternative Spiritualities, Sacralization, Popular Culture, and Occulture (vol. I). T\&T Clark International.

Puglisi, R. (2009). La meditación en la luz Sai Baba como performance ritual: acceso corpóreoexperimental a dios. Religião e Sociedade, 29(1), 30-61. https://doi.org/10.1590/S010085872009000100003

Puglisi, R. (2018). La meditación zen entre cristianos. Hábitos corporales, nuevas prácticas rituales y procesos de subjetivación en los grupos Zendo Betania de Argentina. Claroscuro, (17), 1-26.

Puglisi, R., \& Carini, C. (2017). Monjas y sacerdotes católicos como maestros zen. Historia de la escuela Zendo Betania. Revista Brasileira de História das Religiões, 10(29), 217-236. https://doi.org/10.4025/rbhranpuh.v10i29.33258

Ruffing, J. K. (2000). Meditation: Christian Perspectives. En W. M. Johnston (ed.), Encyclopedia of Monasticism (pp. 847-850). Routledge.

Saizar, M. (2009). La etiología de la enfermedad y el fluir de la energía. Relatos de usuarios y especialistas del yoga en Buenos Aires (Argentina). Mitológicas, (24), 9-27.

Saizar, M., Sarudiansky, M., \& Korman, G. (2013). Salud mental y nuevas complementariedades terapéuticas. La experiencia de dos hospitales públicos en Buenos Aires, Argentina. Psicologia \& Sociedade, 25(2), 451-460. https://doi.org/10.1590/S010271822013000200022 
Santillana Vallejo, P. (2018). En la búsqueda del bienestar subjetivo. Las tecnologías del yo en la práctica de yoga en el centro Mukti Yoga, en Mérida, Yucatán. Península, 13(1), 131-155.

Schmidt-Wilk, J., Alexander, C., \& Swanson, G. (1996). Developing consciousness in organizations: the transcendental meditation program in business. Journal of Business and Psychology, 10(4), 429-444. https://doi.org/10.1007/BF02251779

Semán, P., \& Battaglia, A. (2012). De la industria cultural a la religión. Nuevas formas y caminos para el sacerdocio. Civitas, 12(3), 439-452. http://dx.doi.org/10.15448/19847289.2012.3.13009

Šksupele, A. (2015). Christian Meditation: a Path to Oneself and Others. A Qualitative Study of Christian Meditation and Cultural Encounters in Lives of Adults in Latvia [Tesis de maestría, Volda University College]. BraVo Høgskulen i Volda. https://bravo.hivolda.no/hivoldaxmlui/bitstream/handle/11250/285083/master_skupelea.pdf

Steele, S. (2000). Christian Insight Meditation: A Test Case on Interreligious Spirituality. BuddhistChristian Studies, (20), 217-229. https://doi.org/10.1353/bcs.2000.0032

Thomas, J. W., \& Cohen, M. (2014). A methodological review of meditation research. Frontiers in Psychiatry, 5(74), 1-12. https://doi.org/10.3389/fpsyt.2014.00074

van der Veer, P. (2014). The Modern Spirit of Asia. The Spiritual and the Secular in China and India. Princeton University Press. https://doi.org/10.1515/9781400848553

Várguez Pasos, L. A. (2015). Notas preliminares sobre el bienestar subjetivo en sectores populares de Mérida. En G. Angelotti Pasteur \& G. Reyes Domínguez (eds.), Desigualdad y vulnerabilidad social. Reflexiones y estudios de caso (pp. 157-183). Universidad Autónoma de Yucatán.

Versteeg, P. (2006). Marginal Christian Spirituality: An Example from a Dutch Meditation Group. Journal of Contemporary Religion, 21(1), 83-97. https://doi.org/10.1080/13537900500382235

Viotti N. (2018). Más allá de la terapia y la religión: una aproximación relacional a la construcción espiritual del bienestar. Salud Colectiva, 14(2), 241-256. https://doi.org/10.18294/sc.2018.1519

Wachholtz, A., \& Pargament, K. (2005). Is Spirituality a Critical Ingredient of Meditation? Comparing the Effects of Spiritual Meditation, Secular Meditation, and Relaxation on Spiritual, Psychological, Cardiac, and Pain Outcomes. Journal of Behavioral Medicine, 28(4), 369-384. https://doi.org/10.1007/s10865-005-9008-5

Wood, M. (2007). Possession, Power and the New Age Ambiguities of Authority in Neoliberal Societies. Ashgate.

Woodhead, L. (2011). Spirituality and Christianity: The Unfolding of a Tangled Relationship. En G. Giordan \& W. H. Swatos (eds.), Religion, Spirituality and Everyday Practice (pp. 321). Springer. https://doi.org/10.1007/978-94-007-1819-7_1

Wuthnow, R. (1993). Christianity in the Twenty-first Century. Reflections on the Challenges Ahead. Oxford University Press.

Wuthnow, R. (2005). America and the Challenges of Religious Diversity. Princeton University Press. https://doi.org/10.1515/9781400837243 